\title{
EFEKTIVITAS PROMOSI KESEHATAN TERHADAP PENGETAHUAN TENTANG DETEKSI DINI KANKER SERVIKS
}

\author{
Dhiajeng Anisa Vera $\mathbf{S}^{\mathbf{1}}$, Fitria Melina ${ }^{2}$ \\ ${ }^{1,2}$ Sekolah Tinggi Ilmu Kesehatan Yogyakarta \\ *E-mail: fitriamelina88@gmail.com
}

\begin{abstract}
Abstrak
Kanker merupakan salah satu penyebab utama kematian dan kematian akibat kanker serviks dengan prosentase 10,3\%. Prevalensi tumor atau kanker di Indonesia adalah 1,8 per 1000 penduduk, provinsi DIY memiliki prevalensi tertinggi untuk kanker sebesar 4,9\%. Tahun 2017 angka cakupan deteksi dini kanker serviks terendah berada di Kabupaten Bantul sebanyak (9,03\%), dan kejadian kanker serviks dengan pedoman data cakupan deteksi dini kanker serviks tertinggi berada di kecamatan Sanden sebanyak (7,23\%). Salah satu metode untuk menyebarluaskan informasi tentang deteksi dini kanker serviks adalah dengan melakukan promosi kesehatan. Tujuan penelitian ini ntuk mengetahui efektivitas promosi kesehatan terhadap pengetahuan ibu tentang deteksi dini kanker serviks di Dusun Daleman Kelurahan Gadingharjo Sanden Bantul. Jenis penelitian adalah kuantitatif dengan metode Pre-Experimental One Group PretestPosttes Design. Jumlah populasi $57 \mathrm{ibu}$ PUS, jumlah sampel 53 ibu PUS diambil dengan teknik Total Sampling. Hasil penelitian bahwa pengetahuan ibu sebelum diberikan promosi kesehatan berada di kategori kurang sebesar 58,5\% dan setelah diberikan promosi kesehatan berada di kategori cukup sebesar 73,6\%. Hasil uji Wilcoxon dengan $\alpha=0,05$, diperoleh nilai signifikan sebesar 0,000 . Promosi kesehatan dengan metode ceramah efektif ntuk meningkatkan pengetahuan ibu tentang deteksi dini kanker serviks di Dusun Daleman Kelurahan Gadingharjo Sanden Bantul.
\end{abstract}

Kata Kunci : deteksi dini kanker serviks, pengetahuan, promosi kesehatan

\begin{abstract}
Cancer is one of the main causes of cervical cancer deaths and deaths by 10,3\%. The prevalence of tumors or cancer in Indonesia is 1,8 per 1000 population, the province of DIY has the highest prevalence for cancer of 4,9\%. In 2017 the lowest coverage rates for early detection of cervical cancer were in Bantul Regency (9,03\%), and the incidence of cervical cancer with guidelines for the highest coverage data for early detection of cervical cancer was in the Sanden sub-district (7,23\%). One method for disseminating information about early detection of cervical cancer is to do health promotion.

To know the effectivness oh health promotion on mothers knowedge about early detection of cervical cancer in Dusun Daleman Kelurahan Gadingharjo Sanden Bantul.

The type of research is quantitative with the Pre-Experimental One Group Pretest-Posttes Design method. The population are 57, the sample are 53 respondents and taken by Total Sampling technique.

The knowledge of mothers before they were given health promotion was conducted, only 58,5\%, showed minus knowledge. After given the health promotion was conducted 73,6\%, showed enough knowledge. The result of Wilcoxon Test with confidence level $\alpha=0,05$, result in signifikan 0,000.

Health promotion with an effective lecture method to increase maternal knowledge about early detection of cervical cancer in Dusun Daleman Kelurahan Gadingharjo Sanden Bantul.
\end{abstract}

Keywords :, early detection of cervical cancer, knowledge, health promotion 


\section{PENDAHULUAN}

Kanker merupakan penyakit dengan prevalensi cukup tinggi di dunia. Insiden kanker meningkat dari 12,7 juta kasus tahun 2008 menjadi 14,1 juta kasus tahun 2012. Kanker merupakan salah satu penyebab utama kematian, sebanyak 8,2 juta orang meninggal akibat kanker dan $12 \%$ dari seluruh kematian di dunia disebabkan oleh kanker. Jumlah kematian akibat kanker meningkat dari 7,6 juta orang tahun 2008 menjadi 8,2 juta pada tahun 2012 (World Health Organization, 2014).

Menurut WHO (World Health Organization), di Indonesia kanker serviks menempati urutan kedua setelah kanker payudara. Didapatkan kasus baru kanker serviks sekitar 20.928 dan kematian akibat kanker serviks dengan persentase 10,3\% (WHO, 2014).

Berdasarkan Riset Kesehatan Dasar tahun 2018, prevalensi tumor atau kanker di Indonesia adalah 1,8 per 1.000 penduduk. Prevalensi kanker tertinggi terdapat di Daerah Istimewa Yogyakarta (DIY) (4,9\%), diikuti Sumatera Barat (2,5\%), Gorontalo $(2,4 \%)$, dan DKI Jakarta masing-masing (2,1\%). Kanker tertinggi di Indonesia adalah kanker payudara dan kanker leher rahim pada perempuan, sedangkan pada laki-laki adalah kanker paru dan kanker kolorektal (Depkes RI, 2018).
Angka prevalensi kejadian penyakit kanker di DIY cukup tinggi yakni $4,1 \%$ per 1000 penduduk, angka ini lebih tinggi dari angka prevalensi nasional yang hanya $2 \%$. Jumlah kasus baru penderita kanker serviks ditemukan sebanyak 247 kasus dari 5 kabupaten yang dilaporkan, yaitu di Kabupaten Bantul sebanyak 132 kasus (53,44\%), di Kabupaten Gunung Kidul yaitu 53 kasus (21,45\%), di Kabupaten Kulon Progo yaitu 23 kasus $(9,31 \%)$, di kota Yogyakarta sebanyak 21 kasus $(8,5 \%)$, dan di kabupaten Sleman sebanyak 18 kasus $(7,29 \%)$. Dari data tersebut dapat disimpulkan bahwa kasus kanker serviks tertinggi berada di Kabupaten Bantul (Dinkes DIY, 2016).

Upaya deteksi dini dengan cara pap smear atau IVA belum banyak diketahui masyarakat luas. Salah satu metode untuk menyebarluaskan inforasi tentang deteksi dini adalah dengan melakukan promosi kesehatan. Promosi kesehatan dengan metode ceramah interaktif merupakan upaya yang dapat digunakan agar lebih dapat menjamin peningkatan pengetahuan, sikap dan perubahan perilaku (Lia, 2011).

Metode untuk menyampaikan promosi kesehatan salah satunya yaitu melalui metode ceramah merupakan bentuk pembelajaran dimana interaksinya melalui bentuk penerangan dan penuturan lisan dari penyampai kepada pendengar. Pelaksanaan 
promosi kesehatan yaitu melakukan intervensi sehingga akan meningkatkan pengetahuan pada individu itu sendiri dan perilaku individu sesuai dengan nilai-nilai kesehatan (Haiya dkk, 2017)

Berdasarkan hasil studi pendahuluan yang dilakukan pada hari Kamis 10 Januari 2018 di Dusun Daleman Kelurahan Gadingharjo Sanden Bantul, diketahui bahwa dari 10 orang ibu, 7 di antaranya mengatakan tidak mengetahui tentang pemeriksaan deteksi dini kanker serviks, dan 3 orang ibu di antaranya mengatakan mengetahui tentang pemeriksaan deteksi dini kanker serviks.

Berdasarkan latar belakang masalah di atas peneliti tertarik untuk melakukan penelitian dengan judul "Efektivitas promosi kesehatan terhadap pengetahuan ibu tentang deteksi dini kanker serviks di Dusun Daleman Kelurahan Gadingharjo Sanden Bantul”

\section{METODOLOGI}

Penelitian ini merupakan jenis penelitian kuantitatif dengan metode Pre-experimental design. Rancangan penelitian yaitu One Group Pretest-Posttest Design. Lokasi penelitian ini yaitu di Dusun Daleman Kelurahan Gadingharjo Sanden Bantul dilaksanakan pada bulan April 2019. Populasi dalam penelitian ini seluruh ibu Pasangan Usia Subur (PUS) di Dusun Daleman Kelurahan Gadingharjo Sanden Bantul yang berjumlah 53 ibu Pasangan Usia Subur (PUS). Sampel penelitian ibu-ibu Pasangan Usia Subur (PUS) yang ada di Dusun Daleman Kelurahan Gadingharjo Sanden Bantul. Menggunakan teknik sampling Total Sampling. Instrumen yang digunakan dalam penelitian ini adalah kuisioner.

Analisa data terdiri dari analisa univariat dilakukan pada setiap variabel dari hasil penelitian untuk menghasilkan distribusi dan presentase dari setiap variabel dan analisa Bivariat dengan menggunakan uji Wilcoxon Match Pairs Test.

\section{HASIL}

Tabel 1. Distribusi Frekuensi Usia, Pendidikan dan Pekerjaan Responden

\begin{tabular}{ccc}
\hline Usia & Frekuensi & Prosentase \\
\hline$<20$ tahun & 1 & 1,9 \\
20-49 tahun & 52 & 98,1 \\
Jumlah & 53 & 100 \\
\hline Pendidikan & Frekuensi & Prosentase \\
\hline SD & 2 & 3,8 \\
SMP & 3 & 5,7 \\
SMA & 42 & 79,2 \\
Perguruan Tinggi & 6 & 11,3 \\
Jumlah & 53 & 53 \\
\hline Pekerjaan & Frekuensi & Prosentase \\
\hline IRT & 20 & 37,7 \\
Buruh/Tani & 11 & 20,8 \\
Wiraswasta & 18 & 33,9 \\
Karyawan & 2 & 3,8 \\
Swasta & 2 & 3,8 \\
PNS & 53 & 53 \\
Jumlah & &
\end{tabular}

Berdasarkan tabel 1. diketahui bahwa karasteristik usia ibu PUS di Dusun Daleman mayoritas usia 20-49 tahun sebanyak 52 responden $(98,1 \%)$. Pendidikan ibu mayoritas SMA sebanyak 42 responden (79,2\%). Pekerjaan ibu mayoritas IRT sebanyak 20 responden $(37,7 \%)$. 
Tabel 2.Distribusi Frekuensi Pengetahuan Ibu Tentang Deteksi Dini Kanker Payudara Di Dusun Daleman Kelurahan Gadingharjo Sanden Bantul Sebelum Diberikan Promosi Kesehatan

\begin{tabular}{ccc}
\hline Kategori & Frekuensi (n) & Prosentase $(\%)$ \\
\hline Baik & 7 & 13,2 \\
Cukup & 15 & 28,3 \\
Kurang & 31 & 58,5 \\
Total & 53 & 100,0 \\
\hline
\end{tabular}

Berdasarkan tabel 2 diketahui bahwa pengetahuan ibu tentang deteksi dini kanker serviks di Dusun Daleman Kelurahan Gadingharjo Sanden Bantul sebelum diberikan promosi kesehatan dalam prosentase kurang sebanyak 31 responden $(28,5 \%)$

Tabel 3. Distribusi Frekuensi Pengetahuan Ibu Tentang Deteksi Dini Kanker Payudara Di Dusun Daleman Kelurahan Gadingharjo Sanden Bantul Setelah Diberikan Promosi Kesehatan

\begin{tabular}{ccc}
\hline Kategori & Frekuensi (n) & Prosentase $(\%)$ \\
\hline Baik & 10 & 18,9 \\
Cukup & 39 & 73,6 \\
Kurang & 4 & 7,5 \\
Total & 53 & 100,0 \\
\hline
\end{tabular}

Berdasarkan tabel 3 diketahui bahwa pengetahuan ibu tentang deteksi dini kanker serviks di Dusun Daleman Kelurahan Gadingharjo Sanden Bantul setelah diberikan promosi kesehatan dalam prosentase Cukup sebanyak 39 responden $(73,6 \%)$

Tabel 4. Hasil Uji Efektivitas Promosi Kesehatan Terhadap Pengetahuan Ibu Tentang Deteksi Dini Kanker Serviks Di Dusun Daleman Kelurahan Gadingharjo Sanden Bantul

\begin{tabular}{lll}
\hline $\begin{array}{l}\text { Skor Pengetahuan Ibu } \\
\text { Pretest-Posttest }\end{array}$ & Negatif Ranks & 0 \\
& & \\
& $\begin{array}{l}\text { Positive Ranks } \\
\text { Asymp. Sig. (2- } \\
\text { tailed) }\end{array}$ & 0,000 \\
\hline
\end{tabular}

Berdasarkan tabel 4, dapat dilihat bahwa nilai Negatif Ranks atau selisih negatif antara pengujian pretest dan pengujian posttest adalah 0, yang menunjukan bahwa tidak terdapat ibu PUS dengan penurunan skor pengetahuan. Data ini juga didukung oleh nilai Positive rank adalah 53, yang menunjukan bahwa dari total 53 ibu PUS, secara keseluruhan mengalami peningkatan skor pengetahuan dari pretest ke posttest. Nilai Asymp. Sig. (2-tailed) adalah sebesar 0,000, lebih rendah dari tingkat signifikan sebesar 5\% atau 0,05. Hasil ini menunjukkan bahwa terdapat peningkatan skor pengetahuan ibu PUS diantara sebelum dan sesudah diberikan promosi kesehatan.

\section{PEMBAHASAN}

Berdasarkan hasil pengujian hipotesis menggunakan Wilcoxon Signed Rank Test, didapatkan hasil nilai Asymp. Sig. (2-tailed) sebesar 0,000. Nilai ini lebih kecil dari $\alpha$ $(0,05)$, yang dapat diartikan bahwa terdapat perubahan pengetahuan ibu sebelum dan sesudah diberikan promosi kesehatan dengan metode ceramah. Perubahan pengetahuan ibu adalah berupa peningkatan yang dapat dilihat dari nilai Negative Ranks sebesar 0 dan Positive Ranks sebesar 53. Hasil menunjukan bahwa dari total 53 ibu tidak terdapat ibu yang mengalami penurunan pengetahuan, serta $53 \mathrm{ibu}$ tersebut mengalami peningkatan pengetahuan tentang deteksi dini kanker serviks. Hasil ini menunjukan bahwa "Promosi Kesehatan Dengan Metode Ceramah Efektif Terhadap Pengetahuan Ibu 
Tentang Deteksi Dini Kanker Serviks Di Dusun Daleman Kelurahan Gadingharjo Sanden Bantul".

Penelitian ini sejalan dengan penelitian yang dilakukan oleh Fridayanti dan Laksono (2017), dengan judul "Keefektifan Promosi Kesehatan Teradap Pengetahuan, Sikap dan Perilaku Tentang Tes IVA pada Wanita Usia Subur 20-59 Tahun". Hasil menunjukan bahwa adanya peningkatan pengetahuan wanita tentang deteksi dini kanker serviks dengan IVA Test yang meningkat dari 54,2\% menjadi $91,7 \%$. Peningkatan pengetahuan tersebut disebabkan oleh adanya paparan media atau informasi ditambah dengan adanya dorongan tokoh masyarakat, sehingga setelah diberikan promosi kesehatan mereka mendapat tambahan informasi tentang deteksi dini kanker serviks dengan IVA Test.

Penelitian ini sejalan dengan penelitian yang dilakukan oleh Fridayanti \& Laksono (2017), yang berjudul Efektifitas Promosi Kesehatan Terhadap Pengetahuan Dan Sikap Wanita Terhadap IVA Test Di Wilayah Sukoharjo I Tahun 2016, yang menyatakan bahwa terdapat perubahan tingkat pengetahuan responden di Wilayah Sukoharjo I. Sebelum diberikan promosi kesehatan menggunakan leaflet sebagian besar memiliki pengetahuan tentang deteksi dini kanker serviks melalui IVA Test dalam kategori sedang yaitu 28 responden $(58,3 \%)$, sedangkan setelah diberi promosi kesehatan dengan menggunakan leaflet sebagian besar memili pengetahuan tentang deteksi dini kanker serviks dengan IVA test dalam kategori baik yaitu 28 responden (58,3\%). Faktor yang mempengaruhi perubahan tingkat pengetahuan pada wanita tersebut adalah informasi tentang IVA test.

Menurut Notoatmodjo (2012) faktor yang mempengaruhi pengetahuan salah satunya yaitu informasi. Seseorang yang mempunyai sumber yang lebih banyak akan memperoleh pengetahuan yang lebih luas. Informasi yang diperoleh melalui kenyataan (melihat dan mendengar sendiri), berita melalui surat kabar, radio, TV dapat menambah pengetahuan agar lebih luas, selesainya pendidikan terakhir yang ditempuh juga menambah informasi yang didapat seingga mempengaruhi pengetahuan.

Menurut Pedoman Pelaksanaan Promosi Kesehatan di Daerah, promosi kesehatan adalah upaya meningkatkan kemampuan masyarakat melalui pembelajaran dari, oleh, untuk dan bersama masyarakat, agar mereka dapat menolong diri sendiri, serta mengembangkan kegiatan yang bersumber daya masyarakat, sesuai sosial budaya setempat dan didukung kebijakan publik yang berwawasan kesehatan (Kemenkes, 2005).

Tujuan utama promosi kesehatan untuk mencapai tiga hal yaitu peningkatan pengetahuan atau sikap masyarakat, 
peningkatan perilaku masyarakat serta peningkatan status kesehatan masyarakat (Lia, 2011).

Tingkat pengetahuan menurut Wawan dan Dewi (2012) yang terbagi menjadi 6 tingkatan yaitu tahu lalu dipahami dan diaplikasikan kemudian dianalisis, mensintesis dan melakukan evaluasi terhadap diri mereka sendiri sehingga terdapat perubahan perilaku setelah diberikannya promosi kesehatan.

Pemberian promosi kesehatan merupakan salah satu cara dalam membagikan informasi kepada ibu tentang deteksi dini kanker serviks, yang bertujuam untuk meningkatkan pengetahuan atau sikap ibu tentang deteksi dini kanker serviks. Pemberian promosi kesehatan ini dilakukan dengan ara menyebar pesan, menanamkan keyakinan, sehingga ibu tidak hanya sadar, tahu dan mengerti, tetapi juga mau untuk melakukan suatu anjuran atau suatu pesan yang etrkandung dalam promosi kesehatan tersebut yang ada hubungannya dengan deteksi dini kanker serviks. Setelah diberi promosi kesehatan ibu diharapkan dapat memahami dan memiliki pengetahuan sesuai dengan informasi saat diberikan promosi kesehatan.

Pemberian promosi kesehatan bagi ibu di Dusun Daleman Kelurahan Gadingharjo Sanden Bantul disajikan oleh peneliti dalam metode ceramah. Peserta yang diberikan promosi kesehatan yaitu sebanyak 53 ibu PUS Dusun Daleman. Materi yang diberikan adalah hal-hal yang berhubungan dengan Deteksi Dini Kanker Serviks yaitu pengertian deteksi dini kanker servks; tujuan deteksi dini kanker serviks; faktor yang mempengaruhi kesadaran melakukan deteksi dini aknker serviks; metode deteksi dini kanker serviks; waktu dan syarat melakukan deteksi dini kanker serviks; dan pencegahan kanker serviks.

Pengetahuan ibu tentang deteksi dini kanker serviks diukur berdasarkan kuisioner yang dibagikan dan yang telah diisi oleh ibu. Berdasarkan hasil pengujian yang telah dilakukan oleh peneliti, menunjukan peningkatan pengetahuan ibu tentag deteksi dini kanker serviks, berdasarkan peningkatan pengetahuan tersebut maka dapat disimpulkan bahwa pelaksanaan promosi kesehatan dengan metode ceramah efektif untuk meningkatkan pengetahuan ibu tentang deteksi dini kanker serviks di Dusun Daleman Kelurahan Gadingharjo Sanden Bantul.

\section{KESIMPULAN}

Pengetahuan ibu PUS tentang deteksi dini kanker serviks di Dusun Daleman Kelurahan Gadingharjo Sanden Bantul sebelum diberikan promosi kesehatan sebagian besar berada dalam kategori kurang dengan prosentase 58,5\%. Pengetahuan ibu PUS 
tentang deteksi dini kanker serviks di Dusun

Daleman Kelurahan Gadingharjo Sanden Bantul setelah diberikan promosi kesehatan sebagian besar berada dalam kategori cukup dengan prosentase 73,6\%. Promosi kesehatan efektif untuk meningkatan pengetahuan ibu PUS tentang deteksi dini kanker serviks di Dusun Daleman Kelurahan Gadingharjo Sanden Bantul dengan nilai Asymp Sig (2tailed) lebih rendah dari tingkat signifikan $(0,000<0,05)$.

\section{KEPUSTAKAAN}

Departemen Kesehatan RI. (2018). Profil Kesehatan Indonesia Tahun 2018. Jakarta: Depkes.

Dinkes DIY. (2016). Profil Kesehatan Propinsi Yogyakarta. Dinas Kesehatan Provinsi Yogyakarta.

Fridayanti, W dan Laksono, B. (2017). Keefektifan Promosi Kesehatan Teradap Pengetahuan, Sikap dan Perilaku Tentang Tes IVA pada Wanita Usia Subur 20-59 Tahun. Public Health Perspective Journal.http://journal.unnes.ac.id/nju/ind ex.php/phpj/article/download/13582/7480 Diakses Pada 1 Mei 2019.

Haiya Nutrisia Nu'im, Iwan Ardian dan Novi Rahmawati. (2017). Effect Of Health Promotion: Health Education With Method Of Knowledge On Knowledge Of Posyandu Cadres On Nutrition
Status Of Toddler. Semarang: Unissula Press

Kementriaan Kesehatan RI. (2005). Pedoman Pelaksanaan Promosi Kesehatan di Daerah. Jakarta: Kemenkes.

Lia. T. (2011). Pengaruh Promosi Kesehatan Terhadap Pengetahuan Tentang Kanker Serviks dan Partisipasi Wanita dalam Deteksi Dini Kanker Serviks di Mojosongo RW 22 Surakarta. Surakarta: Tesis:

Universitas Sebelas Maret

Notoatmodjo, S. (2012). Metodologi Penelitian Kesehatan. Jakarta: Rineka Cipta.

Notoatmodjo, S. (2012). Promosi Kesehatan dan Perilaku Kesehatan. Jakarta: Rineka Cipta.

Wawan, A dan Dewi, M (2012). Teori \& Pengukuran Pengetahuan, Sikap dan Perilaku Manusia. Jakarta: Medical Book.

WHO. 2014. Angka Kejadian Kanker Serviks 